\title{
Associação de Alternaria dauci e A. alternata com sementes de coentro e eficiência do tratamento químico
}

\author{
Ailton Reis; Jaqueson F Satelis; Roseane S Pereira; Warley Marcos Nascimento \\ Embrapa Hortaliças, C. Postal 218, 70359-970 Brasília-DF; E-mail: ailton@cnph.embrapa.br
}

\section{RESUMO}

Doze lotes de sementes de coentro foram avaliados quanto à presença de Alternaria spp., utilizando-se 600 sementes de cada lote, pelo método do papel de filtro. Foram constatadas duas espécies, $A$. dauci (AD) em oito lotes e A. alternata (AA) em seis. Em seguida foram semeadas 400 sementes de cada lote em bandejas de poliestireno expandido com 128 células, verificando-se apenas a presença de $\mathrm{AD}$ nos cotilédones, com infecção variando de 0,33 a $4,67 \%$. O lote que apresentou maior incidência de $\mathrm{AA}$ e $\mathrm{AD}$ foi tratado com fungicidas (thiram, benomyl, captam e iprodione) ou misturas dos mesmos e 400 sementes de cada tratamento foram semeadas em gerbox. O melhor tratamento foi obtido com a mistura iprodione + thiram, com $0,5 \%$ e $0 \%$ de incidência de $\mathrm{AA}$ e $\mathrm{AD}$, respectivamente. Sementes tratadas foram semeadas em bandeja de isopor e aos 21 dias após a semeadura foi feita a leitura, observando-se os cotilédones que apresentavam sintomas. Estes foram removidos das plantas e colocados em câmara úmida para comprovação da presença de Alternaria spp. As plantas resultantes de sementes não tratadas apresentaram infecção de $13 \%$ com $\mathrm{AD}$, enquanto aquelas originárias de sementes tratadas com a mistura thiram + iprodione não apresentaram infeção. Os resultados comprovam a eficiência da mistura thiram + iprodione para redução ou eliminação de $A$. dauci e A. alternata em sementes de coentro.

Palavras-chave: Coriandrum sativum, patologia de sementes, controle químico, fungicidas.

\section{ABSTRACT}

Association of Alternaria dauci and A. alternata with coriander seeds and efficiency of chemical treatments

Twelve lots of coriander seeds were evaluated for the presence of Alternaria spp., using 600 seeds per lot in the blotter test. Two Alternaria species were detected, A. dauci (AD) in eight lots and A. alternata (AA) in six lots. A sample of 400 seeds was sown in styrofoam trays and the incidence of spots on cotyledons was evaluated 21 days after sowing. Only lesions caused by AD were observed on leaves. The seed lot with higher incidence of AA and AD was treated with fungicides (thiram, benomyl, captam and iprodione) and 400 seeds in each treatment were placed in four gerbox boxes with sterilized wet filter paper. Seeds were observed under stereoscopic microscope for presence of $\mathrm{AD}$ and $\mathrm{AA}$. The best treatment was the mixture of thiram + iprodione resulting in $0.5 \%$ and $0 \%$ incidence of AA and $\mathrm{AD}$, respectively. Treated seed samples were sown in styrofoam trays to verify transmission of Alternaria spp. from seeds to seedlings. Plants resulting from non treated seeds presented $13 \%$ of infection with AD. Plants from seeds treated with the mixture thiram + iprodione were not infected by AD. The results demonstrated the efficacy of thiram + iprodione mixture for treatment of coriander seeds against $A$. dauci and A. alternata.

Keywords: Coriandrum sativum, seed pathology, chemical control, fungicides.

\section{(Recebido para publicação em 27 de junho de 2005; aceito em 13 de fevereiro de 2006)}

$\mathrm{O}$ coentro é um condimento muito apreciado pelas populações das regiões Norte e Nordeste do Brasil (Lédo $\&$ Sousa, 1997). Seu cultivo se torna ainda mais importante por ser, quase que exclusivamente, feito por pequenos agricultores, podendo ser uma das suas principais atividades econômicas. A produção de sementes de coentro encontra-se em plena expansão no Brasil (Trigo et al., 1997). Por ser uma cultura rústica, o coentro apresenta poucas doenças de importância econômica (Pedrosa et al., 1984). Entretanto, nos últimos anos, principalmente na época chuvosa tem-se observado alta incidência e severidade da queima das folhas, causada por Alternaria dauci (Reis et al., 2003), patógeno que pode ser transmitido por sementes (Trigo et al., 1997; Togni et al., 2005).

Em sementes de cenoura, trabalhos relatam a presença constante de três es- pécies de Alternaria, entre elas $A$. dauci (Cunha et al., 1984; Cunha et al., 1987; Muniz \& Porto, 1999; Haufeld-Vieira \& Lustosa, 2000; Câmara et al., 2003). Esse patógeno pode se manter viável nas sementes de cenoura por um período de até seis anos (Soteros, 1979), sendo esta uma importante forma de sobrevivência até a implantação de uma nova lavoura e reinício do ciclo da doença.

O fungo A. dauci (Kuhn) Groves \& Skolko é um patógeno comum à cenoura e ao coentro, sendo o mesmo destrutivo a estas culturas. Como visto anteriormente, este patógeno é veiculado e transmitido eficientemente pela semente de cenoura. Entretanto, na literatura existe pouca informação sobre a transmissão de patógenos pelas sementes de coentro, assim como existem poucas informações técnicas sobre o coentro na literatura brasileira, especificamente sobre doenças. Nas áreas de epidemiologia e controle há um maior volume de informações em outros países como a Índia, onde esta hortaliça tem maior expressão e é mais pesquisada (Henz \& Lopes, 2000). Entretanto, das várias doenças mencionadas para aquele país, poucas são registradas no Brasil.

Pouco se sabe sobre as interações de A. dauci e outras espécies deste gênero com o coentro. Apenas Trigo et al. (1997) constataram sua associação e de mais três espécies com sementes dessa cultura. Entretanto, não foi investigada a transmissão destes patógenos e nem o efeito do tratamento químico das sementes sobre os mesmos. Recentemente, uma investigação feita com apenas dois lotes de sementes de coentro, revelou alta incidência de $A$. dauci $\mathrm{e}$ A. alternata (Fr.:Fr.) Keissl. em um deles, sendo que estes fungos interferiram na germinação e no desenvolvimento das plântulas (Togni et al., 2005). Com isso, surgiu a 
necessidade de se estudar esta associação, utilizando um número maior de lotes de sementes, com intuito de saber se o patógeno poderia ser transmitido da semente para as plantas e, em caso positivo, a eficiência do controle químico no tratamento de sementes.

Para o controle de fungos em sementes, o método mais utilizado tem sido o tratamento destas com fungicidas (Neergaard, 1977; Bateman et al., 1986; Jeffs, 1986; Soave \& Moraes, 1987). O tratamento químico tem como objetivo o controle de organismos associados às sementes e a proteção destas e das plântulas contra organismos do solo, contribuindo para a redução da transmissão de patógenos para a parte aérea das plantas (Lasca, 1986). Assim, quanto maior eficiência tiver o tratamento, menor será a fonte inicial de inóculo para o desenvolvimento de epidemias no campo (Menten, 1991). No Brasil não existe nenhum produto registrado para o tratamento de sementes de coentro, sendo necessário o estudo de produtos e doses para se efetuar este registro.

Este trabalho teve por finalidade investigar a sanidade de doze lotes comerciais de sementes de coentro, verificar se as espécies $A$. alternata e $A$. dauci podem ser transmitidas pelas sementes de maneira eficiente e avaliar alguns produtos químicos para o seu controle.

\section{MATERIAL E MÉTODOS}

Este trabalho foi realizado no laboratório de Fitopatologia e casas de vegetação da Embrapa Hortaliças em Brasília, de março a outubro de 2004. Em todos os experimentos, os resultados foram submetidos a uma análise de variância e comparação de médias pelo teste de Tukey a 5\%.

Teste de sanidade de sementes de coentro

Doze lotes comerciais de sementes de coentro, provenientes de várias empresas (Tabela 1), foram analisados quanto à sanidade visando determinar $\mathrm{a}$ incidência de espécies de Alternaria e/ ou outros fungos.

\section{Método do papel de filtro}

Inicialmente, foi utilizado o teste do papel de filtro (blotter test), de acordo com a metodologia descrita em Brasil (1992). Foram utilizadas 600 sementes

Tabela 1. Percentagem de incidência de Alternaria dauci e A. alternata em doze lotes comerciais de sementes de coentro. Brasília, Embrapa Hortaliças, 2004.

\begin{tabular}{|c|c|c|c|c|}
\hline \multirow{2}{*}{ Lote } & \multirow{2}{*}{ Cultivar } & \multirow{2}{*}{ Empresa } & \multicolumn{2}{|c|}{ Incidência de fungos (\%) } \\
\hline & & & A. dauci & A. alternata \\
\hline 01 & Verdão & Horticeres & $28,67 a^{*}$ & $42,00 \mathrm{a}$ \\
\hline 02 & Verdão & Isla & $8,33 b$ & $0,33 b$ \\
\hline 03 & Verdão & Isla & $8,00 \mathrm{~b}$ & $2,00 \mathrm{~b}$ \\
\hline 04 & Verdão & Isla & $3,00 \mathrm{c}$ & $0,25 b$ \\
\hline 05 & Verdão & Horticeres & 1,00 & $0,00 \mathrm{~b}$ \\
\hline 06 & Verdão & Hortivale & 1,00 & $0,00 \mathrm{~b}$ \\
\hline 07 & Americano Gigante & Horticeres & 0,25 & $0,00 \mathrm{~b}$ \\
\hline 08 & Americano Gigante-369 & Horticeres & 0,25 & $1,00 \mathrm{~b}$ \\
\hline 09 & Palmeira & Hortivale & 0,00 & $0,00 \mathrm{~b}$ \\
\hline 10 & Tapacurá & Hortivale & 0,00 & $0,00 \mathrm{~b}$ \\
\hline 11 & Asteca & Sakata & 0,00 & $0,00 \mathrm{~b}$ \\
\hline 12 & Tabocas & Hortivale & 0,00 & $0,22 \mathrm{~b}$ \\
\hline
\end{tabular}

*Médias de três repetições. Médias seguidas de mesma letra, na vertical, não diferem entre si, pelo teste de Tukey a 5\% de probabilidade.

por lote, sendo representadas por três repetições com 200 sementes cada. As sementes foram distribuídas em caixas de gerbox sobre papel de filtro esterilizado e umedecido com água destilada e esterilizada. As caixas foram mantidas à temperatura de $25^{\circ} \mathrm{C}$ e 12 horas de fotoperíodo. Dois dias após o plaqueamento, as sementes foram submetidas a um tratamento térmico a $-10^{\circ} \mathrm{C}$ por $24 \mathrm{~h}$ para interrupção do processo germinativo. Em seguida, as caixas foram mantidas em condições de laboratório $\left(25 \pm 4^{\circ} \mathrm{C}\right)$ por mais cinco dias, quando foi feita a leitura. A presença de fungos nas sementes foi observada sob um microscópio estereoscópico, no aumento de 20x.

Método de sintomas em plântulas

Este ensaio visou verificar a transmissão de patógeno das sementes para as plântulas. O teste foi feito com substrato estéril (Plantmax ${ }^{\circledR}$ ) em bandejas de poliestireno expandido, simulando as mesmas condições de desenvolvimento a campo. Após avaliar a incidência de Alternaria spp. pelo método do papel de filtro, 400 sementes de cada lote foram semeadas em quatro bandejas (poliestireno expandido) com 128 células (100 sementes por bandeja), contendo substrato esterilizado. Aos 21 dias foram avaliados os sintomas nas folhas cotiledonares, para verificar se houve infecção por um dos patógenos. As folhas, que apresentavam sintomas, foram removidas das plantas e colocadas em câmara úmida por $24 \mathrm{a} 48 \mathrm{~h}$, dando condições para o fungo esporular e assim comprovar sua presença nas mesmas. A presença de estru- turas do fungo (conídios e conidióforos) nas folhas cotiledonares foi observada em microscópio estereoscópio e microscópio composto.

Eficiência do tratamento das sementes de coentro com fungicidas contra a persistência de Alternaria alternata e $A$. dauci

$\mathrm{O}$ tratamento foi efetuado no lote que apresentou maior incidência das duas espécies de Alternaria, tanto no método do papel de filtro quanto no teste de sintomas em plântulas, sendo o lote escolhido da cultivar Verdão (lote 01). Foram utilizados os fungicidas e as misturas mais comumente usados em tratamentos de sementes: thiram (Rhodiauram SC), iprodione (Rovral SC), captan (Captan 500 PM), benomyl (Benlate 500 PM), thiram+iprodione (Rovrin PM), captan+benomyl, benomyl+thiram+iprodione e captan+thiram+iprodione. A escolha das dosagens utilizadas dos produtos, não registrados para a espécie, foi feita com base na recomendação para tratamentos de sementes de outras hortaliças, como a cenoura. Foram pesados cinco gramas de sementes, que foram misturadas em sacos plásticos com $15 \mathrm{~g}$ do ingrediente ativo de cada fungicida ou suas misturas, que corresponde a 30 miligramas dos produtos comerciais. Em seguida, 400 sementes foram distribuídas em quatro caixas Gerbox $^{\circledR}$ (50 sementes por caixa) contendo papel de filtro esterilizado e umedecido com água destilada. Vinte e quatro horas após, a germinação das sementes foi interrompida pela colocação das cai- 


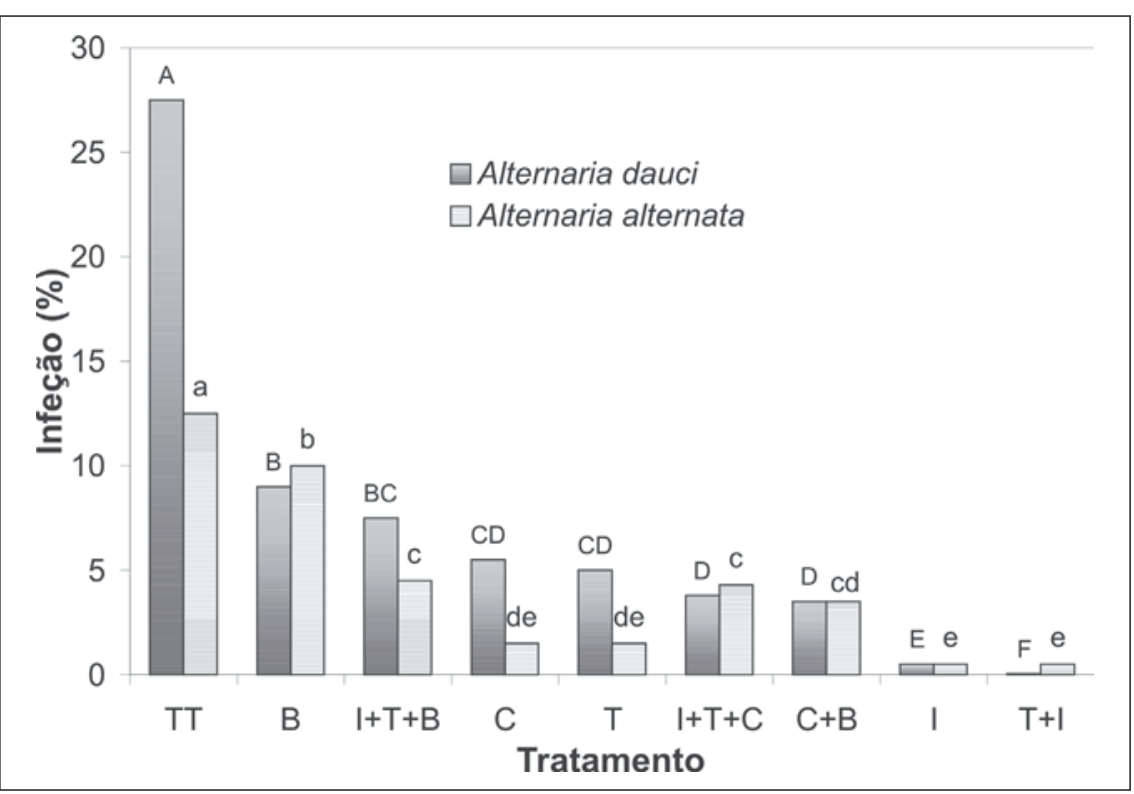

Figura 1. Incidência de Alternaria dauci e A. alternata em sementes de coentro, cv. Verdão, após tratamento com fungicidas e misturas dos mesmos (TT=testemunha sem fungicida, $\mathrm{C}=$ captan, $\mathrm{T}=$ thiram, $\mathrm{I}=$ iprodione e B=benomyl). Brasília, Embrapa Hortaliças, 2004.

Médias seguidas de mesma letra não diferem entre si, pelo teste de Tukey a 5\% de probabilidade. O efeito dos fungicidas foi avaliado individualmente para cada patógeno.

xas em "freezer" a $-10^{\circ} \mathrm{C}$ por $24 \mathrm{~h}$. Em seguida, estas foram mantidas por cinco dias a $25^{\circ} \mathrm{C}$. Foi avaliada a incidência das duas espécies fúngicas.

Eficiência do tratamento de sementes de coentro com fungicidas para controle da transmissão de Alternaria dauci

As sementes tratadas com os fungicidas foram semeadas em bandejas de poliestireno expandido com 128 células, contendo substrato esterilizado $\left(\right.$ Plantmax $\left.^{\circledR}\right)$. Após 21 dias, aquelas folhas cotiledonares que apresentavam sintomas foram submetidas à câmara úmida, conforme descrito anteriormente.

Nos tratamentos, em que foi observada a transmissão de $A$. dauci das sementes para as mudas, as plantas foram mantidas na casa de vegetação por mais 25 dias e avaliou-se a porcentagem de infecção secundária das folhas verdadeiras a partir do inóculo primário nos cotilédones.

\section{RESULTADOS E DISCUSSÃO}

Nos 12 lotes de sementes de coentro avaliados visando determinar seu estado sanitário geral e presença de espécies de Alternaria, só foram constatadas duas espécies, A.dauci (AD) e A. alternata (AA), e mais alguns outros fungos saprófitas, tais como espécies de Cladosporium, Penicillium e Aspergillus, em pequena in- cidência. As duas espécies de Alternaria eram predominantes nos lotes e, assim, tornaram-se objeto de estudo deste trabalho. A maioria dos lotes (75\%) estava infectada por uma das duas espécies de Alternaria, sendo alguns com alta incidência e apenas três lotes (25\%) estavam livres das duas espécies. Cinco lotes (42\%) apresentavam infecção pelas duas espécies de Alternaria, oito lotes (67\%) estavam infectados por $\mathrm{AD}$ e seis deles $(50 \%) \mathrm{com}$ AA. Destacou-se um dos lotes da cultivar Verdão com $29 \%$ e $42 \%$ de AD e AA, respectivamente (Tabela 1). Estes resultados confirmam observações feitas por Trigo et al. (1997) de que a semente de coentro é um eficiente veículo de disseminação de Alternaria spp. Esta constatação é preocupante, uma vez que um patógeno tão importante para o coentro, como AD, estando em alta incidência na semente, poderá causar problemas à cultura quando esta estiver implantada no campo.

Após constatada a presença de AA e $\mathrm{AD}$ em alta incidência em alguns lotes, $\mathrm{o}$ teste de plântulas confirmou a transmissão de $A$. dauci via semente, apesar de não ter sido em todos os lotes contaminados e na mesma proporção em que as sementes estavam infectadas. Aparentemente, as duas espécies fúngicas não interferiram na germinação e vigor das sementes de coentro, pois todos os lotes (contaminados ou não) apresentaram alta emergência de plântulas (acima de 80\%). Houve transmissão do patógeno para as folhas cotiledonares em apenas quatro dos lotes avaliados, e variou de 0,33 a 4,6\%. Oito lotes $(04 ; 05 ; 06 ; 08$; 09; 190; 11 e 12) não apresentaram lesões de AD nas folhas cotiledonares. Maior incidência de $\mathrm{AD}$ nos cotilédones foi observada naqueles lotes que haviam apresentado maior percentagem de incidência nas sementes, sendo o lote 01 , da cv. Verdão, o primeiro deles $(4,6 \%)$, diferindo significativamente dos lotes 02 (1,67\%); $07(1 \%) \mathrm{e}$ $03(0,33 \%)$. Ficou então constatado que $A$. dauci tem um alto poder de infecção via sementes, enquanto $A$. alternata não confirmou essa transmissão, evidenciando que, para o coentro, este fungo está associado às sementes apenas como saprófita, não ocasionando prejuízo nenhum no desenvolvimento da cultura. Entretanto, Trigo et al. (1997) alegam que esta espécie fúngica pode interferir na viabilidade e vigor das sementes. Além disso, Togni et al. (2005) observaram redução de germinação de sementes de coentro e interferência no desenvolvimento das plântulas em um lote contaminado com estes dois fungos. A espécie $A$. dauci pode se tornar problema sério para o cultivo do coentro sendo transmitido da semente para as plântulas de maneira eficiente. Com isto ocorrendo já no início do desenvolvimento da lavoura, o problema torna-se mais grave, pois epidemias iniciando muito cedo podem comprometer a cultura. Além disso, existe a possibilidade de disseminação do patógeno para áreas livres. Por isso, o tratamento de sementes se faz necessário.

A incidência de $A$. dauci e $A$. alternata em sementes tratadas pode ser observada na Figura 1, onde os resultados comprovam que, na maioria dos tratamentos, os patógenos ainda conseguem permanecer viáveis nas sementes. Isto pode ter ocorrido devido à localização do patógeno na semente, pois $A$. dauci geralmente localiza-se no embrião e/ou no endosperma das mesmas, conforme observado por Muniz \& Porto (1999). Esta localização inviabiliza o tratamento da semente com produtos protetores, os quais não atingem estas partes da semente e, assim, não têm efeito sobre o patógeno. Mesmo os produtos sistêmicos podem apresentar dificuldades para atingirem o embrião numa concentração suficiente para eliminar o patógeno. A única exceção, que se observou neste trabalho, foi a mistura de iprodione+thiram, 
que parece ter erradicado o fungo $A$. dauci das sementes.

No ensaio de tratamento de sementes, a testemunha apresentou $12,5 \%$ e $27,5 \%$ de incidência de $\mathrm{AAe} \mathrm{AD}$, respectivamente. O melhor tratamento foi a mistura de iprodione + thiram (Rovrin) com 0,5 e 0\% de incidência de $\mathrm{AAe} A \mathrm{AD}$, respectivamente. Já o tratamento químico menos eficiente foi benomyl, que apresentou, respectivamente, $9,0 \%$ e $10 \%$ de incidência de AA e AD. Os tratamentos contendo benomyl, captan, ou suas misturas, foram os menos eficientes para o controle dos fungos nas sementes (Figura 1). Estes resultados corroboram os de Halfeld-Vieira \& Lustosa (2000) e Cunha et al. (1984), que também observaram que o tratamento de sementes de cenoura com captan pode não ser eficiente para o controle de Alternaria spp. O benomyl é um fungicida que apresenta pequeno efeito sobre a maioria dos fungos da família Dematiaceae, que inclui o gênero Alternaria.

A mistura thiram+iprodione foi a mais eficiente para inibir a transmissão da doença, enquanto que o benomyl praticamente não inibiu a transmissão do patógeno das sementes para as plântulas (Figura 2). Estes resultados comprovam a eficiência da mistura fungicida iprodione+thiram para redução ou eliminação de Alternaria spp. em sementes. A alta eficiência desta mistura para o controle de Alternaria spp. também foi constatada por Cunha et al. (1984) e Strandberg (1984) em sementes de cenoura para controle de $A$. dauci. Os primeiros autores comentaram que isto ocorre devido a um efeito sinergístico entre os dois produtos, tornando-os mais eficientes do que quando ambos são usados isoladamente. Os tratamentos que continham captan ou benomyl, sejam isolados ou em mistura, foram pouco eficientes no controle de $A$. dauci, confirmando os resultados de incidência destes fungos nas sementes tratadas (Figura 1) e corroborando resultados de outros autores (Cunha et al., 1984; Halfeld-Vieira \& Lustosa, 2000) que também observaram a ineficácia de captan sobre Alternaria spp. Em adição, estes fungicidas, quando acrescentados à mistura thiram+iprodione, possivelmente exerceram um efeito antagônico, diminuindo em muito a eficiência inibitória da mesma sobre as duas espécies fúngicas.

Observou-se uma rápida infecção secundária por AD das folhas verdadei-

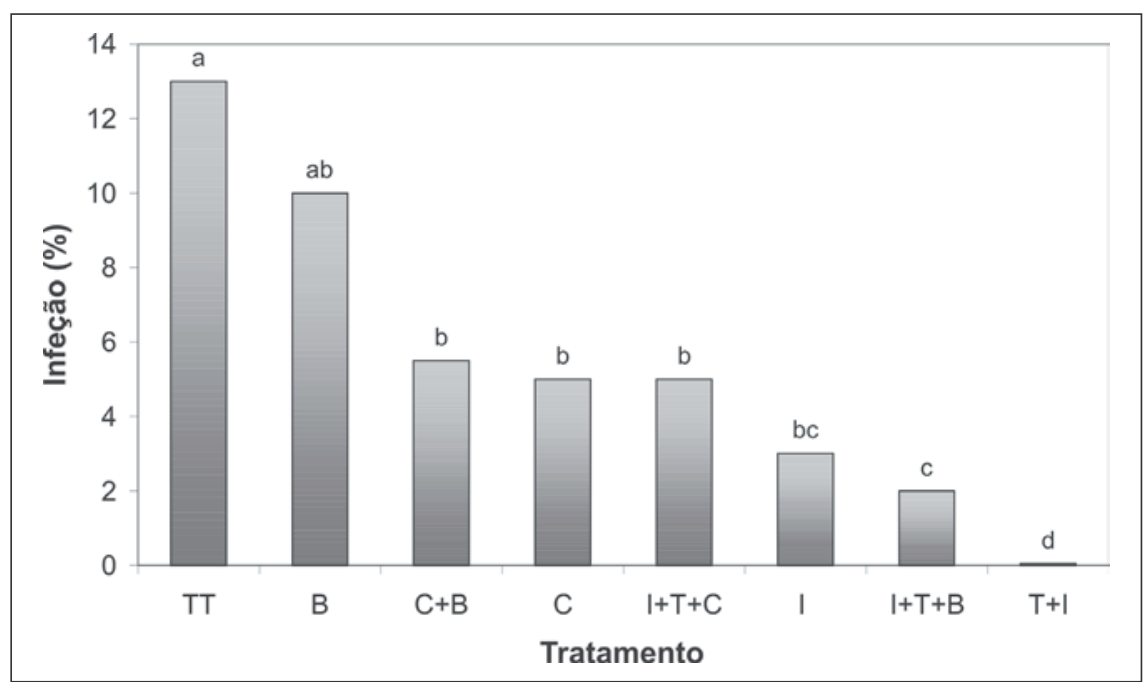

Figura 2. Efeito do tratamento de sementes de coentro, cv. Verdão, com fungicidas e suas misturas sobre a incidência (\%) de Alternaria dauci em folhas cotiledonares (TT=testemunha sem fungicida, $\mathrm{C}=$ captan, $\mathrm{T}=$ thiram, $\mathrm{I}=$ iprodione e $\mathrm{B}=$ benomyl). Brasília, Embrapa Hortaliças, 2004.

Médias seguidas de mesma letra não diferem entre si, pelo teste de Tukey a 5\% de probabilidade.

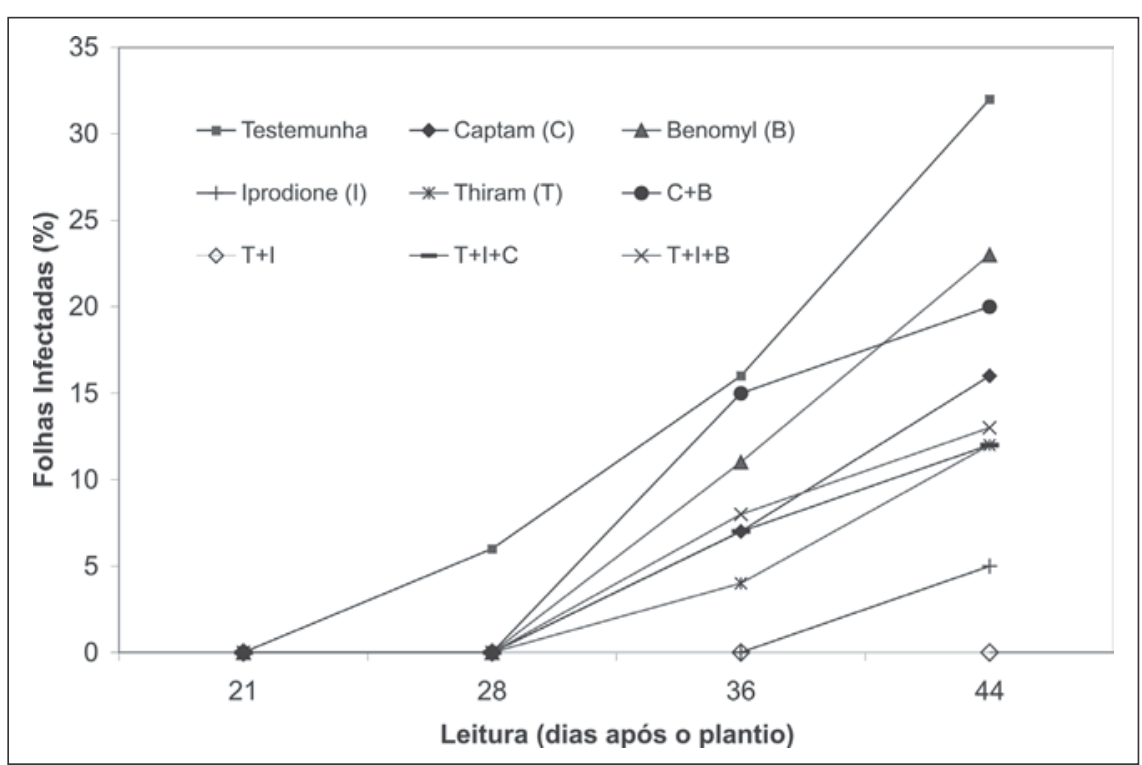

Figura 3. Progresso da incidência de manchas em folhas cotiledonares de coentro da cv. Verdão, causadas por Alternaria dauci, cujas sementes foram tratadas com fungicidas, semeadas em bandejas de isopor e mantidas em casa-de-vegetação. Brasília, Embrapa Hortaliças, 2004.

ras do coentro naqueles lotes que haviam apresentado manchas nos cotilédones (Figura 3). A infecção progrediu rapidamente na maioria dos tratamentos fungicidas, comprovando o alto poder infectivo de AD. Esta infecção secundária só foi possível em casa-de-vegetação devido à ocorrência de altas taxas de umidade relativa no período em que foi realizado o experimento (final de março) e à irrigação ter sido feita duas vezes ao dia e com jatos de água voltados para a folhagem das plantas. Isto certamente proporcionou condições para a disseminação do fungo, além de um período de molhamento foliar suficiente para permitir a germinação dos esporos do patógeno e penetração no tecido da folha. Este efeito progressivo da doença e o poder de infecção secundária do patógeno nas folhas tornam ainda mais necessárias as medidas preven- 
tivas para não deixar que esta inicie e progrida na lavoura. A maneira mais prática de não permitir que isto ocorra é o uso de sementes sadias, sempre que possível, ou o tratamento eficiente das mesmas, quando houverem fungicidas registrados para a cultura.

\section{LITERATURA CITADA}

BATEMAN GL; EHLE H; WALLACE HAH 1986. Fungicidal treatment of cereal seeds. In: JAFFS HA. (ed). Seed treatment. 2 ed. Surrey British Crop Protection Council. p. 83-111.

BRASIL. 1992. Ministério da Agricultura e Reforma Agrária. Secretaria Nacional de Defesa Vegetal. Regras para análise de sementes. Brasília, $365 \mathrm{p}$.

CÂMARA MPS; FRARE VC; SILVA PP; LOPES CA; REIS A; NASCIMENTO WM; BOITEUX LS. 2003. Qualitative and quantitative survey of carrot seed-borne-fungi. Summa Phytopathologica, 29:,88.

CUNHA MM; REIFSCHNEIDER FJB; DELLA VECCHIA PT. 1984. Detecção e avaliação do índice de contaminação de sementes de cenoura por Alternaria alternata, Alternaria dauci e Alternaria radicina. Fitopatologia Brasileira, 9: 377.
CUNHA MM; REIFSCHNEIDER FJB; DELLA VECCHIA PT. 1987. Aspectos fitossanitários na produção de sementes de cenoura. Horticultura Brasileira, 5: 11-14.

HALFELD-VIEIRA BA; LUSTOSA DC. 2000. Incidência de Alternaria dauci e A. radicina nas sementes de cenoura comercializadas na Zona da Mata em Minas Gerais. Fitopatologia Brasileira, 25: S460.

HENZ GP; LOPES CA. 2000. Doenças das apiáceas. In: ZAMBOLIN L; VALE FXR; COSTA H. (eds). Controle de doenças de plantas hortaliças. Viçosa, UFV. cap.14. p. 445-521.

JEFFS KA. 1986. Seed treatment. 2 ed. Surrey, British Crop Protection Council. p. 332.

LASCA C. 1986. Tratamento de sementes. In: Simpósio Brasileiro de Patologia de Sementes. Campinas. Palestra: Campinas, Fundação Cargil. 2: 92-99.

LÉDO FJS; SOUSA JA. 1997. Coentro (Coriandrum sativum L.). In: CARDOSO MO; Hortaliças não convencionais da Amazônia. Brasília, Embrapa, p. 127-132.

MENTEN JOM. (ed.) 1991. Patógenos em sementes: detecção, danos e controle químico. Piracicaba: ESALQ, $321 \mathrm{p}$.

MUNIZ MFB; PORTO MDM. 1999. Presença de Alternaria spp. em diferentes partes da sementes da cenoura e em resíduos culturais e efeito do tratamento de sementes em sua transmissão. Revista Brasileira de Sementes, 21: 187-197.
NEERGAARD P. 1977. Seed pathology. $1^{\text {st }}$ edition. London. The MacMillan Press Ltd. V. I. $839 \mathrm{p}$.

PEDROSA JF; NEGREIROS MZ; NOGUEIRA ICC. 1984. Aspectos gerais da cultura do coentro. Informe Agropecuário, 10: 75-78.

REIS A; BOITEUX LS; SILVA PP; CÂMARA MPS. 2003. Alternaria dauci, agente de manchas foliares em salsa e coentro no Brasil. Fitopatologia Brasileira, 28: S202-S203.

SOAVE J; MORAES SA. 1987. Medidas de controle de doenças transmitidas por sementes. In: SOAVE J; WETZEL MM. (Coord). Patologia de sementes, Campinas, Fundação Cargill. p.192-216. SOTEROS JJ. 1979. Pathogenicity and control of Alternaria radicina and $A$. dauci in carrots. New Zealand Journal of Agricultural Research, 22: 191-196.

STRANDBERG JO. 1984. Efficacy of fungicides against persistence of Alternaria dauci on carrot seed. Plant Disease, 68: 39-42.

TOGNI DAJ; FRARE VC; MORAES MHD; MELO PCT; MENTEN JOM. 2005. Incidência e transmissão de patógenos em sementes de coentro (Coriandrum sativum L.). Summa Phytopathologica, 31: 76, suplemento.

TRIGO MFOO; TRIGO LFN; PIEROBOM CR. 1997. Fungos associados às sementes de coentro (Coriandrum sativum L.) no Rio Grande do Sul. Revista Brasileira de Sementes, 19: 214-218. 